\section{Commentary: Try acting like a normal human being}

\author{
Christopher W. Seder, MD
}

In the past few years, 2 trainees committed suicide at my institution. The scariest part about it was that no one was engaged enough to see it coming. Whether or not we want to admit it, physician wellness is a problem. This may be particularly true in cardiothoracic surgery, a field in which we pride ourselves on mental and physical toughness. I spent my entire medical school, residency, lab time, and fellowship beaten down. It was not always fun, but no one ever said it was supposed to be, and I took pride in my ability to not break. I knew that I would soon be part of the club.

Fast-forward 10 years. Having grown up in culture where I was regularly reminded that "we are not training bakers, we are training surgeons," I am now tasked, as a program director, to ensure that my trainees are raised in a culture of "physician wellness." This is not an unreasonable request, right? You can find tech startups with more arcade games, ping pong tables, and espresso machines than employees. At these companies, no one has offices, everyone goes by their first name, and hierarchy is discouraged. All of this is intended to provide a culture of wellness for employees, and all of this sounds like the exact opposite of the culture of cardiothoracic surgery training. So, how do we change the culture of medicine from the current state to one genuinely focused on physician wellness?

In this month's issue of the Journal, Fajardo and colleagues ${ }^{1}$ have proposed a checklist for assessing the culture of wellness within cardiothoracic training programs and have developed a sample "wellness policy" that fulfills Accreditation Council for Graduate Medical Education (ACGME) requirements. The authors recognize that the ACGME common program requirements are rather abstract

\footnotetext{
From the Department of Cardiovascular and Thoracic Surgery, Rush University Medical Center, Chicago, Ill.

Disclosures: The author reported no conflicts of interest.

The Journal policy requires editors and reviewers to disclose conflicts of interest and to decline handling or reviewing manuscripts for which they may have a conflict of interest. The editors and reviewers of this article have no conflicts of interest.

Received for publication April 30, 2020; revisions received April 30, 2020; accepted for publication April 30, 2020; available ahead of print May 15, 2020.

Address for reprints: Christopher W. Seder, MD, 1725 W Harrison St, Suite 774, Chicago, IL 60305 (E-mail: Christopher_W_Seder@rush.edu).

J Thorac Cardiovasc Surg 2021;161:1988

$0022-5223 / \$ 36.00$

Copyright (c) 2020 by The American Association for Thoracic Surgery

https://doi.org/10.1016/j.jtcvs.2020.04.161
}

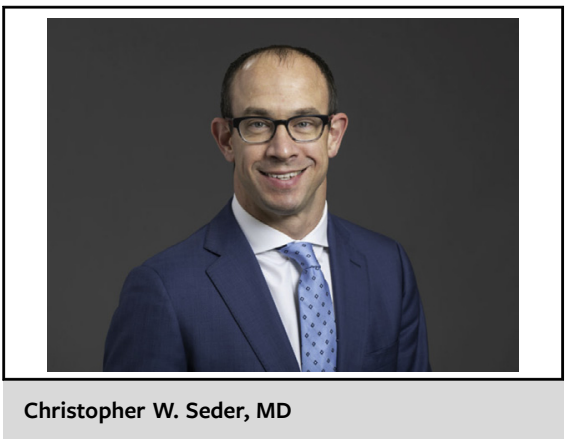

\begin{abstract}
CENTRAL MESSAGE
When surgeon-educators engage their trainees not only as young surgeons but also as people, both will gain a mutual sense of pride and satisfaction, ultimately enhancing physician wellness.
\end{abstract}

and provide concrete suggestions and examples with the goal of helping programs implement meaningful change. They should be applauded for their efforts to bring awareness to a real problem in cardiothoracic surgery and to put a framework around fostering physician wellness.

However, we all know culture eats strategy for breakfast. Online modules, checklists, and grand rounds will have only limited effects. At the end of the day, surgeoneducators must take a deep look inside and ask themselves, just because this is the way it has always been, is this the way it should stay? Once individuals accept the obvious answer (no), they need to engage their trainees not only as young surgeons, but also as husbands, wives, moms, dads, friends, and people. Sure, our field can be stressful, but try acting like a normal human being. I predict that this paradigm shift will result in a mutual sense of pride and satisfaction greater than that accomplished by hazing rituals, for both surgeons and trainees. Through this, I suspect that physician wellness will be enhanced, patient care will improve, and cardiothoracic surgery will become more attractive to future applicants. But this has to come from the top down —and it starts with you.

\section{Reference}

1. Fajardo R, Vaporciyan A, Starnes S, Erkmen CP. Implementation of wellness into a cardiothoracic training program: a checklist for a wellness policy. J Thorac Cardiovasc Surg. 2021;161:1979-86. 